Pesq. Vet. Bras. 23(2):82-86, abr./jun. 2003

\title{
Aborto por Aspergillus fumigatus e A. niger em bovinos no sul do Brasil ${ }^{1}$
}

\author{
Luís G. Corbellini², Caroline A. Pescador², Fernanda J. Frantz², Marcelo de Lima ${ }^{3}$, \\ Laerte Ferreiro² e David Driemeier ${ }^{2}$
}

\begin{abstract}
Corbellini L.G., Pescador C.A., Frantz F.J., Lima M., Ferreiro L. \& Driemeier D. 2003. [Abortus by Aspergillus fumigatus and $A$. niger in cattle in southern Brazil.] Aborto por Aspergillus fumigatus e A. niger em bovinos no sul do Brasil. Pesquisa Veterinária Brasileira 23(2):82-86. Departamento de Patologia Clínica Veterinária UFRGS, Av. Bento Gonçalves 9090, Porto Alegre, RS 91540-000, Brazil. E-mail:davetpat@ vortex.ufrgs.br

Mycotic infection has worldwide distribution and may cause placentitis and abortion in almost all domestic animals. From September 2001 through November 2002 specimens from 147 aborted bovine fetuses along with 34 placentas were submitted to the Laboratory of Veterinary Pathology, Universidade Federal do Rio Grande do Sul, to investigate infectious causes of abortion in southern Brazil. Mycotic abortion was diagnosed in five cases $(3.4 \%$. Aspergillus fumigatus was isolated from four cases and A. niger from one. Virological, bacteriological and direct immunofluorescent antibody tests for Leptospira sp were negative in those cases where Aspergillus sp was cultured. The gestational age of those fetuses ranged from 5 to 8 months. Macroscopic lesions were observed in four cases. One had several nodular lesions disseminated throughout the liver, two had skin lesions characterized by white-grayish round plaques mostly on the head and neck, and thickened cotyledons in two placentas sent with those fetuses. The histological lesions were observed in the liver, lungs and placenta and consisted primary of necrotizing hepatitis, suppurative bronchopneumonia of varying degrees and necrotizing placentitis. With the use of Grocott's methenamine-silver staining, septate hyphae could be observed in three cases, surrounding necrotizing lesions in the liver of one fetus and in two placentas. In two cases hyphae were observed in placental tissues and not in fetal tissues, indicating the importance of the placenta in diagnosing mycotic abortion in cattle.
\end{abstract}

INDEX TERMS: Bovine abortion, mycotic abortion, Aspergillus spp.

RESUM0.- As infecções micóticas apresentam distribuição mundial e podem causar placentite e aborto em diversas espécies de animais. Entre setembro 2001 e novembro 2002, foram processados no Setor de Patologia Veterinária, Universidade Federal do Rio Grande do Sul, 147 fetos bovinos abortados com o objetivo de avaliar as principais causas de abor-

\footnotetext{
${ }^{1}$ Aceito para publicação em 24 de março de 2003.

Parte da tese de doutorado do primeiro autor, Programa de Pós-Graduação em Ciências Veterinárias UFRGS, Porto Alegre, RS. Trabalho com suporte financeiro FAPERGS (Projeto 01/679.4).

${ }^{2}$ Depto Patologia Clínica Veterinária, UFRGS, Av. Bento Gonçalves 9090, Porto Alegre, RS 91540-000.

${ }^{3}$ Centro de Ciências Rurais, Setor de Virologia, UFSM, DMVP/CCR/UFSM, Santa Maria, RS 97105-900.
}

to infeccioso bovino no sul do Brasil. Destes, 34 estavam acompanhados da placenta. Aborto micótico foi diagnosticado em cinco casos (3,4\% mediante cultivo puro de quatro amostras de Aspergillus fumigatus e uma de A. niger associado a lesões histológicas características de fungo. Os exames virológico, bacteriológico e imunofluorescência direta para Leptospirasp foram negativos nestes casos. A idade dos fetos variava entre 5 e 8 meses de idade. Lesões macroscópicas foram observadas em quatro casos e eram caracterizadas por áreas circulares multifocais branco-acinzentadas na pele, principalmente na região da cabeça e dorso, em dois fetos, lesões nodulares no fígado em um caso e espessamento dos cotilédones em duas placentas enviadas juntamente com os fetos. Lesões histológicas foram observadas principalmente no fígado, pulmão e placenta, caracterizadas por hepatite necrótica multifocal, broncopneumonia supurativa e placentite necróti- 
ca. Através da coloração de Grocott hifas septadas foram observadas em duas placentas e nas bordas das lesões necróticas no fígado de um feto. Em dois casos hifas foram observadas somente na placenta e não no feto, salientando-se a importância deste tecido para o diagnóstico de aborto micótico bovino.

TERM OSDE INDEXAÇÃO: Aborto bovino, aborto micótico, Aspergillus spp.

\section{INTRODUÇÃO}

As infecções micóticas apresentam distribuição mundial e podem causar placentite e aborto em diversas espécies de animais (Ainsworth \& Austwick 1973, Zook \& Migaki 1985). Perdas econômicas significativas podem ser decorrentes destas infecções, pois prevalência de aborto micótico de até $24,9 \%$ já foi relatada (Ainsworth \& Austwick 1973). Aspergillus fumigatus é a principal espécie encontrada em casos de aborto micótico bovino, sendo o tecido placentário normalmente o mais afetado (Hillman 1969, Ainsworth \& Austwick 1973). 0 diagnóstico depende da avaliação macroscópica, exame histopatológico e do cultivo, principalmente a partir da placenta e conteúdo do abomaso (Ainsworth \& Austwick 1973, Cruz \& Rosa 1981). No Brasil, casos de broncopneumonia e aborto bovino associado à infecção por Aspergillus sp foram descritos (Santos \& Faria, 1959 Resende et al. 1977).

0 objetivo deste trabalho foi de descrever casos de infecção micótica em fetos bovinos abortados e salientar a importância da sua pesquisa rotineira como possível etiologia de aborto bovino no sul do Brasil.

\section{MATERIAL E MÉTODOS}

Veterinários e técnicos de Cooperativas foram informados sobre 0 estudo que avalia as principais causas de aborto infeccioso bovino no sul do Brasil. Durante o início do projeto, os profissionais de campo foram orientados a enviar fetos bovinos abortados ao setor de Patologia Veterinária da Faculdade de Veterinária, Universidade Federal do Rio Grande do Sul (UFRGS).

0 aborto foi definido como a interrupção da gestação ocorrida entre 42 e 260 dias de gestação. Casos de nascimentos de bezerros prematuros antes de 260 dias de gestação foram considerados também como aborto. Abortos gemelares foram contados como um caso. Os fetos foram necropsiados e a idade foi estimada segundo 0 comprimento da cabeça até a cauda conforme Barr et al. (1990). Fragmentos de cérebro, pulmão, timo, coração, fígado, baço, rim e músculo estriado esquelético foram coletados, fixados em formalina tamponada a $10 \%$ e processados rotineiramente para exame histológico.

0 exame micológico foi realizado através do cultivo em ágarSabouraud contendo cloranfenicol $(0,5 \mathrm{~g} / \mathrm{l})$ a partir de amostras do pulmão, fígado e placenta especificamente nos casos suspeitos de aborto micótico observados na macroscopia. Em casos onde não havia lesões macroscópicas sugestivas, considerou-se o crescimento puro de Aspergillus sp cultivado em ágar-sangue como indicativo de infecção micótica. Coloração especial de Grocott em forno de microondas (Arrington 1992) foi realizada nos tecidos dos fetos e placentas nos casos onde foi isolado fungo e em todas as placentas enviadas juntamente com os fetos, mesmo nos casos onde não houve isolamento micótico ou não havia lesões histológicas nos fetos. Este procedimento foi realizado porque a placenta é o tecido mais afetado na infecção micótica e ocasionalmente pode não causar lesão nos tecidos fetais, podendo diminuir as chances de sucesso no diagnóstico. Como os fungos estão difundidos no ambiente, o diagnóstico de aborto micótico foi baseado no cultivo puro de fungo associado à presença de lesões macroscópicas e/ou histológicas sugestivas de infecção micótica. 0 conteúdo do abomaso dos fetos foram coletados assepticamente e analisados em microscópico de contraste de fase. Todo o material recebido foi submetido aos exames virológico (isolamento e imunoistoquímica para BVDV e BHV-1), bacteriológico (aeróbico, Brucella sp e Campylobacter sp) e imunofluorescência direta para Leptospira sp. 0 cultivo aeróbio das amostras foi realizado em ágar-sangue ovino $(5 \%$, que também propicia bom crescimento de Aspergillus sp. Para o isolamento de Brucella sp foram usados meios base de ágar sangue (Alton et al. 1988, Timoney et al. 1988) e para Campylobacter sp meio BHI (brain heart infusion), conforme Plastridge et al. (1961) ambos acrescidos com $5 \%$ de sangue ovino e antibióticos.

\section{RESULTADOS}

No período de setembro de 2001 a novembro de 2002 foram analisados 147 fetos bovinos abortados, dos quais 34 estavam acompanhados das placentas. Isolamento de fungo do pulmão e fígado foi obtido em 6 casos, todos da espécie Aspergillus sp. Baseado nos achados macroscópico, histopatológico e microbiológico, aborto micótico foi determinado em cinco dos seis casos onde foi isolado Aspergillus sp (números 1 a 5), totalizando uma prevalência de 3,4\%(5/147). Em um caso, 0 isolamento de Aspergillus sp foi considerado contaminante visto que o crescimento estava fora da semeadura e as lesões histológicas observadas eram compatíveis com infecção causada por Neospora caninum. Aspergillus fumigatus foi identificado em quatro casos (números 1, 2, 3 e 5) e A. niger em um (caso 4). Os exames virológico, bacteriológico e imunofluorescência direta para Leptospira sp foram negativos nos cinco casos de aborto micótico. A placenta foi enviada somente em dois casos (números 3 e 5). A idade dos fetos variava entre 5 e 8 meses de gestação. Segundo informações do proprietário, um feto de 8 meses (caso 1) foi expulso ainda com vida, morrendo 3 dias após. Um resumo dos resultados bacteriológico, micológico e dados dos fetos encontrase no Quadro 1. Lesões macroscópicas foram observadas em quatro casos (números 1, 3, 4 e 5) e eram caracterizadas por lesões circulares multifocais branco-acinzentadas na pele (números 3 e 4), principalmente na região da cabeça e dorso (Fig. 1), espessamento dos cotilédones da placenta que variava de leve a severo (casos 3 e 5) e lesões nodulares no fígado (caso 1). Os nódulos estavam dispersos por todo parênquima hepático, variavam de 1 a $3 \mathrm{~cm}$ de diâmetro, tinham consistência firme, bordos esbranquiçados, centro avermelhado e, ao corte, apresentavam aspecto caseoso (Fig. 2). $\mathrm{Na}$ microscopia, as lesões nodulares no fígado (caso 1), caracterizavam-se por uma hepatite fibrinonecrótica, focalmente extensa com focos de inflamação granulomatosa e presença de células gigantes. No linfonodo hepático havia uma linfadenite necrótica e hiperplasia folicular. Nos outros casos as lesões histológicas foram observadas no pulmão (casos 2, 3 , 4), fígado (caso 3) e placenta (casos 3 e 5). No pulmão, dois 

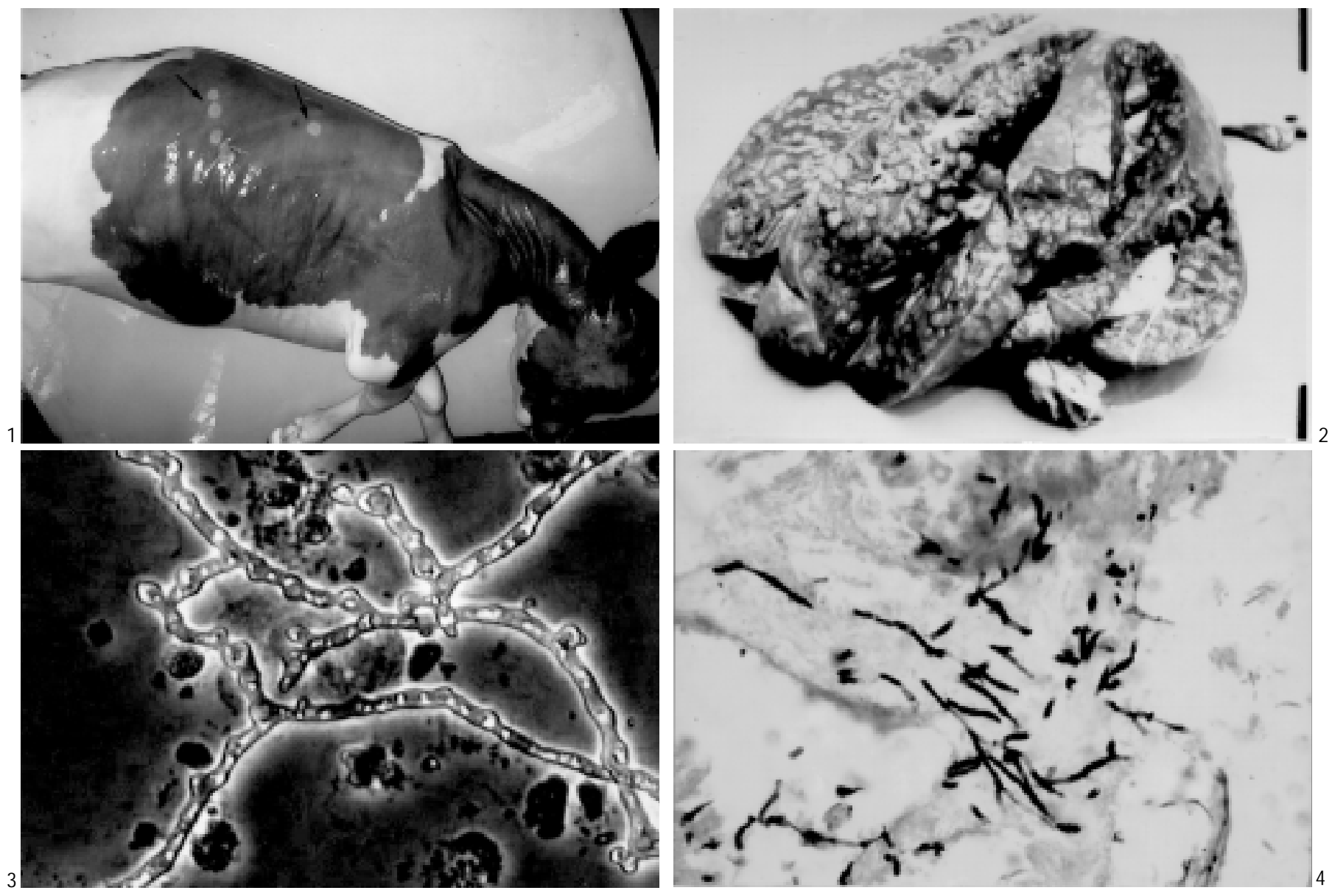

Fig. 1. Feto bovino abortado com 6 meses de idade apresentando lesões circulares multifocais de coloração branco-acinzentada na pele (setas), características de infecção micótica.

Fig. 3. Numerosas hifas septadas presentes no conteúdo do abomaso de um feto com infecção micótica causada por Aspergillus sp. Contraste de fase, obj. 40.

Fig. 2. Fígado de um feto bovino de 8 meses de idade com inúmeros nódulos de aspecto caseoso dispersos por todo parênquima.

Fig. 4. Hifas de Aspergillus sp ao redor de um vaso na placenta. Coloração de Grocott, obj. 40.

Quadro 1. Resultados microbiológicos (bacteriológico aeróbio e micológico) encontrados nos casos de aborto bovino micótico

\begin{tabular}{|c|c|c|c|c|c|c|c|c|}
\hline \multirow[t]{2}{*}{ Caso } & \multirow{2}{*}{$\begin{array}{c}\text { Data de } \\
\text { aborto }\end{array}$} & \multirow{2}{*}{$\begin{array}{c}\text { Idade } \\
\text { (meses) }\end{array}$} & \multicolumn{3}{|c|}{ Agar-sangue } & \multicolumn{3}{|c|}{ Agar-Sabouraud } \\
\hline & & & Pulmão & Fígado & Abomaso & Pulmão & Fígado & Placenta \\
\hline 1 & 06.12 .01 & $8^{a}$ & $\mathrm{NHC}^{\mathrm{b}}$ & $\mathrm{NHC}$ & $\phi^{c}$ & $\phi$ & A. fumigatus & $\phi$ \\
\hline 2 & 07.06 .02 & 7 & $\mathrm{NHC}$ & $\mathrm{NHC}$ & A. fumigatus & $\phi$ & $\phi$ & $\phi$ \\
\hline 3 & 14.07 .02 & 6 & $\mathrm{NHC}$ & $\mathrm{NHC}$ & A. fumigatus & A. fumigatus & A. fumigatus & A. fumigatus \\
\hline 4 & 06.11 .02 & 5 & $\mathrm{NHC}$ & $\mathrm{NHC}$ & $\mathrm{NHC}$ & A. nigere & A. niger & $\phi$ \\
\hline 5 & 20.11 .02 & 6 & $\mathrm{NHC}$ & $\mathrm{NHC}$ & A. fumigatus & A. fumigatus & A. fumigatus & A. fumigatus \\
\hline
\end{tabular}

äezerro expulso com vida (prematuro).

b $\mathrm{NHC}=$ Não houve crescimento.

cNão realizado.

padrões de pneumonia foram observados. Um caracterizavase por pneumonia intersticial difusa, moderada, com presença de infiltrado inflamatório composto basicamente por macrófagos, células multinucleadas gigantes e raros neutrófilos (caso 2) e nos outros dois fetos (casos 3 e 4) 0 quadro observado caracterizava-se por uma acentuada broncopneumonia purulenta associada à presença de vasculite e trombos. No fígado do feto número 3 também foi observado uma hepatite fibrinonecrótica multifocal e que se estendia aos linfonodos hepáticos. Adicionalmente, no conteúdo do abomaso deste feto, foram observadas numerosas hifas septadas na microscopia direta em contraste de fase (Fig. 3). 
Quadro 2: Achados histopatológicos e histoquímicos dos abortos com isolamento de Aspergillus sp

\begin{tabular}{|c|c|c|c|c|}
\hline \multirow{2}{*}{$\begin{array}{l}\text { Caso } \\
\text { no. }\end{array}$} & \multirow[t]{2}{*}{ Órgãos examinados } & \multirow[t]{2}{*}{ Alterações histológicas (HE) } & \multicolumn{2}{|c|}{ Coloração de Grocott } \\
\hline & & & Órgãos realizados & Resultado \\
\hline 1 & $\begin{array}{l}\text { Pulmão, fígado, linfo- } \\
\text { nodo hepático }\end{array}$ & $\begin{array}{l}\text { Hepatite fibrinonecrótica, multifocal, } \\
\text { severa e focos de inflamação granulo- } \\
\text { matosa; linfadenite necrótica }\end{array}$ & $\begin{array}{l}\text { Fígado, linfonodo he- } \\
\text { pático }\end{array}$ & $\begin{array}{l}\text { Hifas septadas no fí- } \\
\text { gado e linfonodo }\end{array}$ \\
\hline 2 & $\begin{array}{l}\text { Cérebro, coração, timo, } \\
\text { pulmão, fígado, rim, a- } \\
\text { drenal, baço, abomaso } \\
\text { e músculo esquelético }\end{array}$ & $\begin{array}{l}\text { Pneumonia intersticial difusa, modera- } \\
\text { da com presença de células gigantes } \\
\text { multinucleadas; depleção de células lin- } \\
\text { fóides no baço }\end{array}$ & Pulmão, fígado e rim & Negativo \\
\hline 3 & $\begin{array}{l}\text { Cérebro, coração, timo, } \\
\text { pulmão, fígado, rim, ba- } \\
\text { ço, abomaso, músculo } \\
\text { esquelético e placenta }\end{array}$ & $\begin{array}{l}\text { Broncopneumonia purulenta difusa,se- } \\
\text { vera; hepatite purulenta difusa, severa; } \\
\text { placentite de intensidade leve caracte- } \\
\text { rizada por necrose multifocal em algu- } \\
\text { mas vilosidades do cotilédone }\end{array}$ & $\begin{array}{l}\text { Pulmão, fígado, rim e } \\
\text { placenta }\end{array}$ & $\begin{array}{l}\text { Hifas septadas nas vi- } \\
\text { losidades do cotilédo- } \\
\text { ne da placenta }\end{array}$ \\
\hline 4 & $\begin{array}{l}\text { Cérebro, coração, pul- } \\
\text { mão, fígado, rim, baço, } \\
\text { abomaso e músculo es- } \\
\text { quelético }\end{array}$ & $\begin{array}{l}\text { Broncopneumonia purulenta difusa, se- } \\
\text { vera associada a presença de vasculite } \\
\text { e trombos }\end{array}$ & Pulmão, fígado e rim & Negativo \\
\hline 5 & $\begin{array}{l}\text { Cérebro, coração, timo, } \\
\text { pulmão, fígado, rim, ba- } \\
\text { ço, abomaso, músculo } \\
\text { esquelético e placenta }\end{array}$ & $\begin{array}{l}\text { Placentite severa caracterizada por ex- } \\
\text { tensa necrose nas vilosidades dos coti- } \\
\text { lédones associada a presença de hifas } \\
\text { fracamente basofílicas }\end{array}$ & $\begin{array}{l}\text { Pulmão, fígado, rim e } \\
\text { placenta }\end{array}$ & $\begin{array}{l}\text { Numerosas hifas septa- } \\
\text { das nas vilosidades do } \\
\text { cotilédone e ao redor } \\
\text { de vasos na placenta. }\end{array}$ \\
\hline
\end{tabular}

Nas duas placentas enviadas para exames (casos 3 e 5 ) observou-se necrose nos cotilédones que variava de leve a acentuada. No caso 5, a necrose estendia-se por toda a vilosidade dos cotilédones. A coloração especial de Grocott revelou a presença de hifas septadas com diâmetro regular nos bordos das lesões nodulares hepáticas e no linfonodo hepático do caso um e na placenta dos casos 3 e 5 (Fig. 4). No Quadro 2 encontra-se uma síntese dos órgãos analisados e achados microscópicos e histoquímicos destes casos. Nas 34 placentas avaliadas através da coloração de Grocott, observou-se a presença de hifas de fungo somente nos casos onde foi isolado Aspergillus sp (casos 3 e 5), como descrito anteriormente.

Os cinco casos de aborto micótico eram provenientes de quatro propriedades leiteiras situadas no Rio Grande do Sul e uma no Paraná. Nestas propriedades os animais eram vacinados contra Brucella sp, Leptospira sp, BVDV e BHV-1 e havia histórico de aborto de forma esporádica. 0 número total de animais variava de 47 a 130, todos da raça Holandês. Das cinco vacas com aborto micótico, uma apresentava más condições corporais, recuperando-se posteriormente e duas apresentavam histórico de aborto anterior. Em uma propriedade o aborto micótico ocorreu 10 dias após vacinação contra febre aftosa, sendo registrado reação adversa caracterizada por febre e apatia (Caso 2). Em duas propriedades onde se diagnosticou casos de aborto micótico foi observado mofo nos grãos de milho (caso 1) e nos resíduos de cervejaria (caso 5).

\section{DISCUSSÃO}

A prevalência de infecção micótica observada em fetos bovinos abortados recebidos no Setor de Patologia Veterinária/ UFRGS foi de 3,4\%(5/147). 0 aborto micótico tem distribuição mundial e trabalhos relatam prevalências que variam entre $1 \%$ e 24,9\%(Ainsworth \& Austwick 1973, Moojen et al. 1983, Jarret et al. 1984, Knudtson \& Kirkbride 1992). Em 27 anos de estudo, Hillman (1969) observou uma variação anual na prevalência de aborto micótico entre 0 e 16,4\% Aspergillus fumigatus é a principal espécie identificada em aborto micótico bovino, sendo isolado em aproximadamente $60 \%$ a $75 \%$ dos casos (Hill et al. 1971, Ainsworth \& Austwick 1973). Knudtson \& Kirkbride (1992) encontraram uma prevalência de aborto micótico de $6,8 \%$ de um total de 6858 casos de aborto bovino, sendo que $A$. fumigatus foi isolado em $62 \%$ dos casos. No presente trabalho, A. fumigatusfoi identificado em quatro casose Aspergillums niger em um. Resende et al. (1977) descreveram um caso de aborto e placentite micótica causada por $A$. fumigatus em um bovino no estado da Bahia. No conhecimento dos autores, este é 0 primeiro relato de infecção micótica em feto bovino abortado causado por A. niger no Brasil. 0 diagnóstico foi baseado no cultivo puro de Aspergillus sp a partir do conteúdo do abomaso e/ou de tecidos fetais associado à presença de lesões macroscópicas e/ou histológicas características de infecção micótica. As lesões nodulares observadas no fígado do bezerro prematuro (caso 1) são similares às descritas em infecções crônicas por Aspergillus sp (Ainsworth \& Austwick 1973), sugerindo infecção intra-uterina. Lesões disseminadas pelo parênquima hepático, de 0,5-1cm de diâmetro e apresentando centro necrótico foram descritas em casos de infecção por Mortierella wolfii em bezerros de 3 dias de idade (Carter et al. 1973). Lesões macroscópicas na pele de fetos abortados, similares às observadas em dois fetos neste estudo, são encontradas em aproximadamente 7 a $20 \%$ dos casos de aborto bovino micótico (McCausland et al. 1987, Knudtson \& Kirkbride 1992). Broncopneumonia do tipo granulomatosa ou supurativa de severidade variável e necrose hepática centrolobular são achados histopatológicos ocasionalmente observados em casos de aborto micótico (Hillman 1969, McCausland et al. 1987, 
Knudtson \& Kirkbride 1992), sendo que a placenta é o principal tecido afetado (Hillman 1969). Em um estudo onde 102 placentas apresentavam hifas septadas de Aspergillus sp, apenas 8 de 55 fetos que acompanhavam estas placentas continham lesões microscópicas associadas à presença de hifas (McCausland et al. 1987). Segundo Hillman (1969) a prevalência de infecção micótica foi de $19 \%$ e $6 \%$ quando a placenta e feto ou apenas o feto foram enviados para diagnóstico, respectivamente. Estes resultados salientam a importância da análise da placenta no diagnóstico de aborto micótico, já que este tecido proporciona um ambiente favorável para o crescimento e difusão dos fungos (Hillmann \& McEntee 1968, Hill et al. 1971, Johnson et al. 1994). Isto sugere que a prevalência de infecção micótica encontrada neste trabalho pode estar subestimada, já que apenas 34 placentas foram enviadas com os 147 fetos.

Os casos de aborto micótico normalmente ocorrem entre 6 e 8 meses de gestação e acometem poucos animais (Hillman 1968, Williams et al. 1977, Knudtson \& Kirkbride 1992). Nas propriedades avaliadas neste estudo, os abortos ocorreram de forma esporádica e indícios de que a infecção micótica ocorrera de forma oportunista são substanciados pelo fato de que um animal apresentava más condições corporais e outro apresentou reações adversas após vacinação contra febre aftosa no período em que ocorrera 0 aborto. Relatos sugerem que as infecções micóticas são oportunistas e provavelmente estejam relacionados com fatores imudodepressores (Zook \& Migaki 1985, Knudtson \& Kirkbride 1992). A fonte de infecção normalmente ocorre através da ingestão de silagem ou grãos mofados (Hugh-Jones \& Austwick 1967, Neilan et al. 1982), sugerindo que 0 milho e resíduos de cervejaria mofados observados em duas propriedades possa ter originado a infecção que provocaram dois casos de aborto micótico registrados neste estudo.

Este trabalho relata a prevalência e descreve casos de aborto micótico recebidos no Setor de Patologia Veterinária da UFRGS, além de enfatizar que esta casuística é muito pouco registrada no país, apesar de poder causar perdas econômicas significativas. Em conseqüência dos resultados obtidos, fica evidenciada a necessidade de um estudo detalhado para avaliar a prevalência e variação sazonal das ocorrências de abortamento micótico no Brasil.

Agradecimentos-. Ao laboratório de virologia da Universidade Federal de Santa Maria pelos isolamentos virais dos materiais dos fetos bovinos abortados deste estudo. Aos alunos de graduação André Correa, Milene Schmitz e Elsio Wunder Jr pela ajuda dispensada no projeto.

\section{REFERÊNCIAS}

Ainsworth G.C. \& Austwick P.K.C. 1973. Mycotic abortion, p 74-80. In: Fungal Diseases of Animals. $2^{\text {nd }}$ ed. Commonwealth Agriculture Bureaux, Farnham Royal, Slough, England.
Alton G.G., Jones L.M., Angus R.D. \& Verger J.M. 1988. Techniques for the Brucellosis Laboratory. Institut National de la Recherche Agronomique, Paris, p. 169-174.

Arrington J.B. 1992. Bacteria, fungi, and other microorganisms, p. 203-246. In: Prophet E.B., Mills B., Arrington J.B. \& Sobin L.H. (ed.) Laboratory Methods in Histotechnology. Armed Forces Institute of Pathology, American Registry of Pathology, Washington.

Barr C.B., Anderson M.L., Blanchard P.C., Daft B.M., Kinde H. \& Conrad P.A. 1990. Bovine fetal encephalitis and myocarditis associated with protozoal infections. Vet. Pathol. 27:354-361.

Carter M.E., Cordes D.O., Menna M.E. \& Hunter R. 1973. Fungi isolated from bovine mycotic abortion with special reference to Mortierella wolfii. Res. Vet. Sci. 14:201-206.

Cruz L.C.H. \& Rosa C.A.R. 1981. Aborto micótico em bovinos: considerações sobre o diagnóstico e revisão da literatura relevante. Revta Bras. Med. Vet. $4(1): 16-19$.

Hill M.W.M., Whiteman C.E., Benjamin M.M. \& Ball L. 1971. Pathogenesis of experimental bovine mycotic placentitis produced by Aspergillus fumigatus. Vet. Path. 8:175-192.

Hillman R.B. 1969. Bovine mycotic placentitis in New York State. Cornell Vet. 59:269-288.

Hillman R.B. \& McEntee K. 1969. Experimental studies on bovine mycotic placentitis. Cornell Vet. 59:289-302.

Hugh-Jones M.E. \& Austwick P.K.C. 1967. Epidemiological studies in bovine mycotic abortion. Vet. Rec. 81:273-276.

Jarret I.V., McOrist S., Waddington J., Browning J.W., Malecki J.C. \& McCausland I.P. 1984. Diagnostic studies of the fetus, placenta and maternal blood from 265 bovine abortions. Cornell Vet. 74 (1):8-20.

Johnson C.T., Lupson G.R. \& Lawrence K.E. 1994. The bovine placentome in bacterial and mycotic abortion. Vet. Rec. 12:263-266.

Knudtson W.U. \& Kirkbride C.A. 1992. Fungi associated with bovine abortion in the northern plains state (USA). J. Vet. Diagn. Invest. 4:181-185.

McCausland I.P., Slee K.J. \& Hirst F.S. 1987. Mycotic abortion in cattle. Aust. Vet. J. 64 (5):129-132.

Moojen V., Roberts A.W. \& Carter G.R. 1983. Microbial causes of bovine abortion in Michigan. Vet. Med. 78 (1):102-106.

Neilan M.C., McCausland I.P. \& Maslen M. 1982. Mycotic pneumonia, placentitis and neonatal encephalitis in dairy cattle caused by Mortierella wolfii. Aust. Vet. J. 59:48-49.

Plastridge W.N., Koths M.E. \& Williams L.F. 1961. Antibiotic mediums for the isolation of vibrios from bull semen Am. J. Vet. Res. 22:867-871.

Resende J., Neto R.B. \& Gigante A.L. 1977. Aborto com placentite micótica em bovino. Anais I Encontro de Pesquisas, Escola de Medicina Veterinária, UFBA, Salvador, s/p.

Santos J.A. \& Faria J.F. 1959. Aspergilose do aparelho respiratório de bezerros. Arqs Inst. Biol. Animal, Rio de J., 2:15-20.

Timoney J. F., Gillespie J.H., Scott F.W. \& Barlough J.E. 1988. Hagan and Bruner's Microbiology and Infectious Diseases of Domestic Animals. $8^{\text {th }}$ ed. Cornell University Press, Ithaca. 951p.

Williams B.M., Shreeve B.J., Hebert C.N. \& Swire P.W. 1977. Bovine mycotic abortion: some epidemiological aspects. Vet. Rec. 100:382-385.

Zook B.C. \& Migaki G. 1985. Aspergillosis in animals, p. 207-256. In: Al-Doory Y. \& Waagner G.E. (ed.) Aspergillosis. Charles C. Thomas Publisher, Springfield, Illinois. 